\title{
OPTIMAL MAINTENANCE WORKS FOR THE ABORSHADA ROAD IN THE WESTERN REGION OF LIBYA
}

\author{
Medhat Abdelrahman YOUSSEF ${ }^{1^{*}}$, Abdelbary Altayb ELBASHER ${ }^{1}$
}

\section{Abstract}

In this research, the condition of a road pavement was investigated for the Aborshada Road in the Gharian region of Libya to determine the optimal maintenance works. Previously, a simple engineering judgment was the only procedure followed by the Gharian municipal engineers for evaluating pavements and prioritizing maintenance. The surface condition of the Aborshada Road pavement was investigated using "the Pavement Condition Index (PCI)" visual technique. The pavement was inspected to survey the different distresses in each sample unit. Ninteen pavement distresses were classified according to the PCl standards (PCI for roads and parking lots became an ASTM standard in 2007 (D6433-07)). It was necessary to know the most common distresses of the Aborshada Road to provide assistance for the decision maker in his evaluation of the pavement and the optimum repair method to be selected.

This study reveals the actual performance of the pavements and suggests the research required for dealing with the pavement maintenance problem in Libya, especially in the western region. The best maintenance alternative for Aborshada Road was Case No. 3 (Potholes, Long. \& Trans. Cracking and Alligator Crack Maintenance). Also, the most common pavement distresses on the Aborshada Road were Distress Nos. 1, 3, 6, 7, 10 and 13 ac cording to the ASTM - D6433-07 classification.
Address

1 Department of Civil Engineering, Faculty of Engineering, Algable Elgarby University, Gharian, Libya.

Corresponding author:med_most@yahoo.com

\section{Key words}

- Pavement distress,

- Optimum Maintenance Policy,

- Pavement Condition Index,

- pavement management,

- pavement scores.

\section{INTRODUCTION}

One of the main transportation systems in Libya is the highway system. The main function of this system is to connect cities, towns and villages throughout Libya. Therefore, it is necessary to have highways in an excellent condition from both the structural and functional points of view.

Every agency responsible for the maintenance of roadway systems faces the problem of insufficient funding to perform all of the necessary repairs on all pavement sections. Therefore, highway agencies must adopt a pavement management system (PMS) to help set priorities. The PMS includes a method for evaluating pavement performance on a routine basis and identifying sections with a need for rehabilitation or maintenance (Youssef and Essam, 2001). One of the key components of any pavement maintenance management system is the pavement rating system. These systems involve calculating a numerical score or index based on the pavement distress and surface condition to make a comparison between roadway segments based on their condition (Samer et al., 2011). A pavement rating system may be based solely on visible surface distresses or may use an index based 
on ride quality alone to perform the regular evaluation of pavements and select projects, or it can use a combination of distress and ride quality. The Ohio Department of Transportation (ODOT) utilizes the Pavement Condition Rating (PCR), which is based on surface distress for project selection. When evaluating the condition of pavements, there is a need to apply a systematic approach to identify and quantify the distresses that occur on a pavement. In addition to compiling the type, severity, and quantities of distress observed, the use of a single index to describe the pavement condition is also attractive for use in managing a pavement network (Reza et al., 2006).

The pavement surface condition data are an important input into a Pavement Management System (PMS) to estimate the maintenance and rehabilitation needs based on a sound analysis. These needs are used for the development of the maintenance budget and the work plan, which serves as a guide to district personnel for the selection of suitable maintenance works. Once a particular pavement link is selected for maintenance, a detailed project level analysis is conducted to determine the specific treatment. One of the key components of any pavement management system is the pavement rating system. These systems involve calculating a numerical score or index based on the pavement distress and surface condition to make a comparison between roadway segments based on their condition. Also, pavement condition surveys play a vital role in the management of a pavement network. A pavement condition survey provides the most valuable information for pavement performance analysis and is vital in order to forecast pavement performance, anticipate maintenance and rehabilitation needs, establish maintenance and rehabilitation priorities, and allocate funding. Pavement Condition Evaluation Techniques can be divided into :

- Visual survey

- Falling Weight Deflectometer (FWD)

- Ground Penetration Radar (GPR)

- Dynamic Cone Penetrometer (DCP)

Visual condition surveys (or distress surveys) vary from the simplistic to extremely detailed and complex. On the simple end of the scale, some agencies use a windshield survey where raters drive along the shoulder of the road and rate the pavement on a scale of 0 to 10 based upon the surface distresses given. No notation of the types or extents of distresses are noted. The obvious shortcoming with this method is that when rehabilitation is recommended, the analyst has no method of determining what types of distresses influenced the overall rating. The analyst only knows that the road is in a certain condition state (Angela et al., 2002).

The Pavement Condition Index (PCI) was developed in the late 1980s by the U.S. Army Corps of Engineers. It has a scale ranging from 0 to 100. In 2000, the American Society for Testing of Materials (ASTM) adopted the PCI method as a standard practice for roads and parking lot pavement condition index surveys (ASTM Standard D6433-99). The PCI was developed to provide engineers with a numerical indication of an overall pavement condition. During a PCI survey, visible signs of deterioration within a selected sample unit are measured, recorded, and analyzed. Distress types and their severity and quantity are all identified and recorded. The final calculated PCI value is a number from 0 to 100 , with 100 representing a pavement in an excellent condition, as shown in Figure 1. The results of a PCI survey are used for a myriad of purposes, including planning and programming at the network level, generating information used in a project-level rehabilitation design, and assigning maintenance work for each pavement link as in this research. The pavement data are used for the selection of pavement sections and optimum maintenance works, which have a big effect on the pavement condition for Aborshada Road. Typically, the districts have used the data in combination with their local knowledge of pavement conditions to select pavement maintenance projects.

In this search, the road pavement was inspected to survey the different distresses in each sample unit. There are 19 different distresses classified as per the PCI standards. The PCI for roads and parking lots became an ASTM standard in 2007 (D6433-07). The PCI Index is often used at the network level for identifying when treatments should be applied, the impact of not applying treatments, and projecting future conditions. Also, at the project level, they are often used in determining the long-term impact of various treatment alternatives as applied in this search. Information about specific distresses can be used to determine appropriate maintenance actions for consideration.

\section{METHODOLOGY}

Pavement surface condition data surveys play a vital role in the pavement management system at the network and project levels. Survey field data is presently being obtained manually. Based on the field investigation data, pavement condition analyses, maintenance and rehabilitation needs, and maintenance priorities have been performed.

The main function of any pavement management system is pavement condition tracking and suggesting the suitable maintenance works. So, the pavement evaluation must be objective, systematic, and repeatable, such as the pavement condition index (PCI) rating system described in ASTM Standard D6433-07. To evalute the pavement condition, the road network must be defined into manageable sections
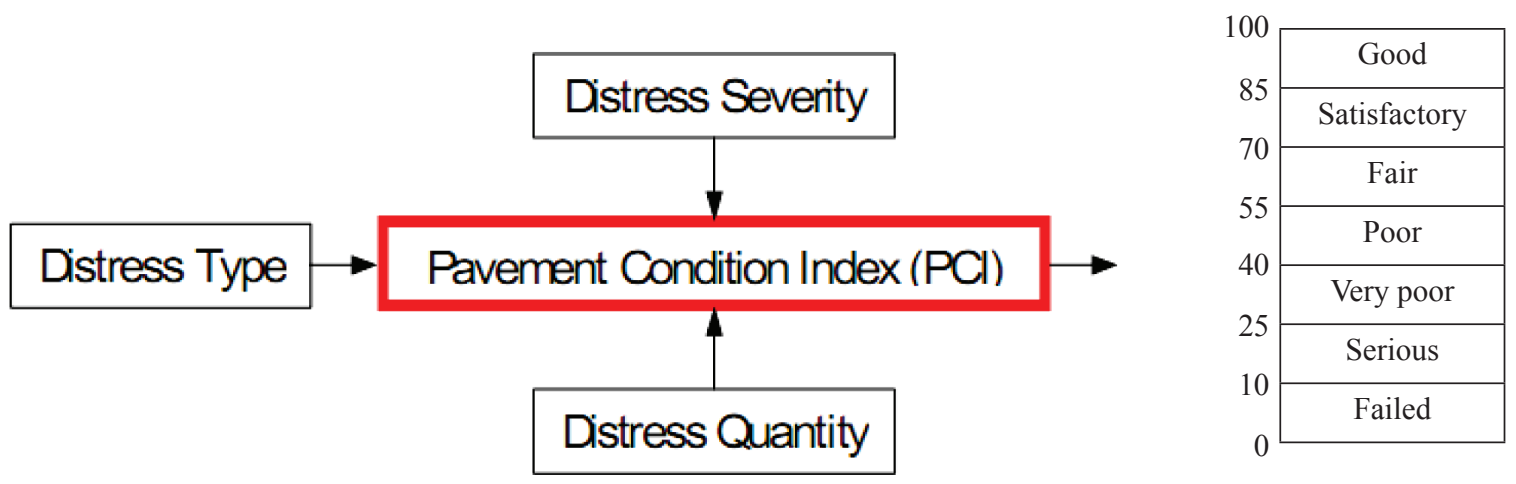

Fig. 1 Pavement Condition Index (PCI), Rating Scale. 
at both the network and project levels. The road network is divided into branches. Branches are divided into links using factors such as construction history, road pavement type, and so on. Generally, this task is very time consuming, but must be completed.

This section includes a brief review of PCI procedures. In this research, the Pavement Condition Index (PCI) was used to evaluate the pavement performance. The PCI was developed for the U. S. Air Force for airfield pavements and later modified for roads and streets (Shahin and Kohn, 1979; Athanassios et al., 2009). The Pavement Condition Index (PCI) was determined by a visual condition survey which identifies the types, severities and quantities of distresses. Firstly, the pavement section was divided into sample units. The number of sample units to inspect can be determined based on the desired level of reliability. The road pavement is periodically inspected to survey the different distresses in each sample unit. The pavement distresses were classified into 19 distresses according to the PCI standards. Then, these measures were used for allocating resources for maintenance, monitoring the results of the maintenance, identifying policy issues, and making budget projections.

\subsection{Road Description and Pavement Inspection}

The road description accounts for the geometric characteristics of the longitudinal and transversal profile : In this case, Aborshada Road's length is $22 \mathrm{~km}$ with two pavement lanes with a width of $7 \mathrm{~m}$ and a gravel shoulder on both sides. The road is 2 lanes and 2 ways, starting from the city of Gharian to the Hera Gate as shown in Figure 2.

A manual survey was performed following ASTM D 6433. The pavement link was divided into sections. Each section was divided into sample units. The type and severity of the sample distress was assessed by visual inspection. The quantity of each distress was measured. Typically, this procedure required a team of at least two engineers.

Each sample unit was walked upon, and the team kept record sheets for each sample unit surveyed and recorded the appropriate code for the distress type, its severity and a measurement of quantity. The Pavement Condition Index (PCI) is determined by a visual condition survey, which identifies the types, severities and quantities of distresses. First the pavement section is divided into sample units. The number of sample units to inspect can be determined based on the desired level of reliability. Deduct values are determined through curves developed for every distress type and the severity for all the density levels. The deduct values are then added to acquire a total deduct value (TDV). A correction curve is used to take into account the effect of multiple distresses and adjust the TDV into a corrected deduct value (CDV). The PCI is calculated by the equations:

$$
\mathrm{PCI}=100-\mathrm{CDV}
$$

If all of the sample units in the pavement link are surveyed, then the PCI is averaged. If less than all the sample units are inspected, the PCI link is calculated using the following equation:

$$
\mathrm{PCI}_{\mathrm{S}}=\left[(\mathrm{N}-\mathrm{A}) \times \mathrm{PCI}_{1}+\mathrm{A} \times \mathrm{PCI}_{2}\right] / \mathrm{N}
$$

where:

$\mathrm{PCI}_{\mathrm{S}}$ : the PCI of the pavement link,

$\mathrm{PCI}_{1}$ : the average PCI of the random samples,

$\mathrm{PCI}_{2}$ : the average PCI of additional samples,

$\mathrm{N}$ : the total number of samples in the section, and

A : the number of "additional" samples inspected.

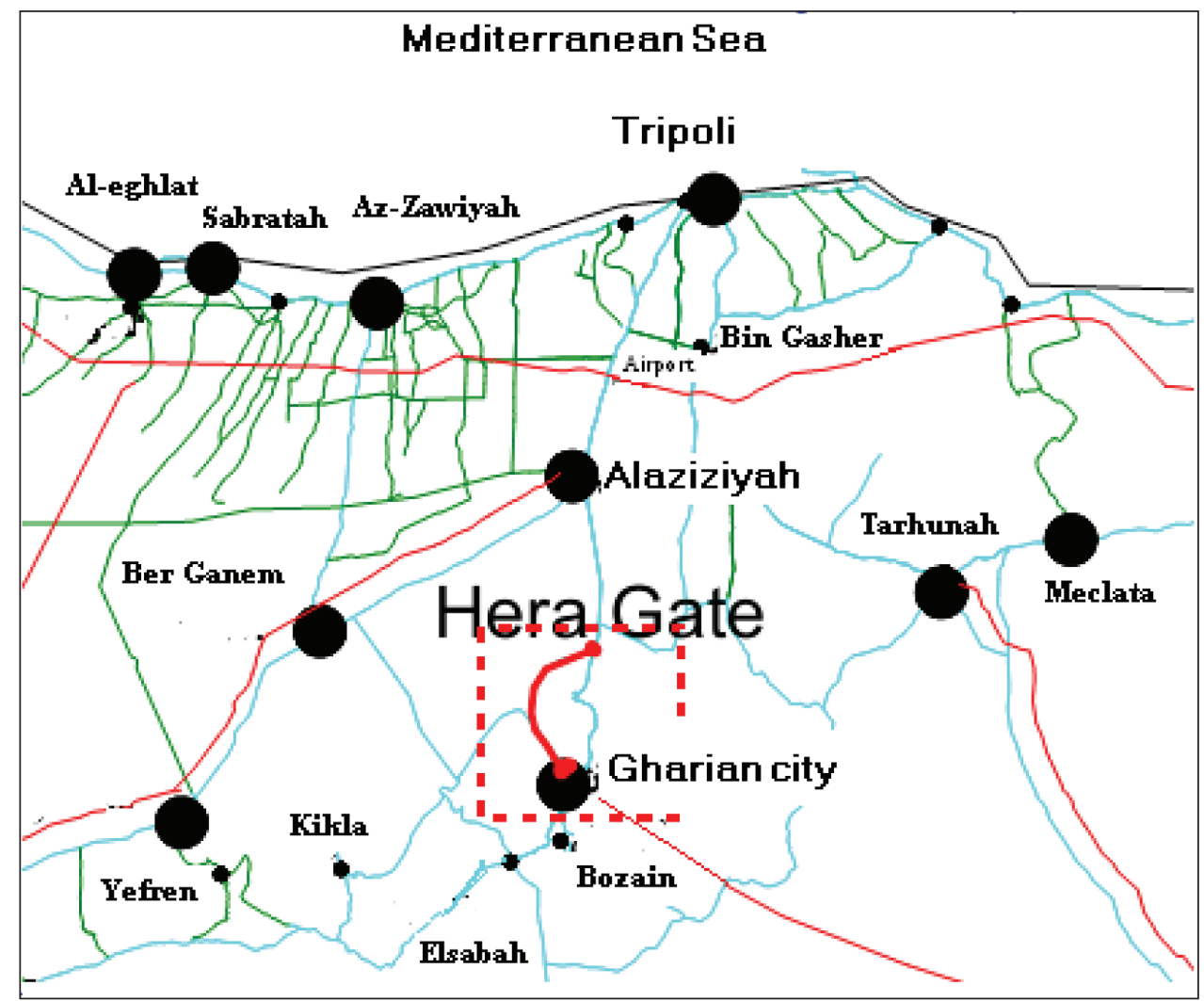

Fig. 2 Aborshada Road with red colour in dot box in the map, start from city of Gharian to Hera Gate (section from Libya map). 


\subsection{Pavement Condition Evaluation ( $\mathrm{PCI}$ calculations)}

A pavement link is divided into a number of uniform sample units, (i.e., an area of a $100 \mathrm{~m}$ length and $7 \mathrm{~m}$ width, with a total sample number of 22). The following calculations are conducted for each sample unit. For each distress and severity level present, the area/length affected is added up and divided by the area of the sample unit, which expressed in percenteges, is referred to as a distress density. Subsequently, the deduct values are computed for each distress density, using a series of charts. These deduct values need to be processed to compute the maximum corrected deduct value (max CDV). The correction is necessary to ensure that the sum of the deduct values does not exceed $100 \%$. If fewer than one of the deduct values is larger than $2 \%$, the max CDV is equal to the sum of the individual deduct values. Otherwise, the max CDV is computed through an iterative process as follows. The deduct values are arranged in a decreasing order. The maximum number of allowed deduct values $\mathrm{m}$, which cannot exceed 10, is given below as a function of the highest deduct value (HDV), (i.e., the first in the decreasing order list):

$$
m=1+\frac{9}{98}(100-H D V) \leq 10
$$

A widely used distress index that is derived from the deduct values is the Pavement Condition Index (PCI). The general expression for computing PCI is as follows:

$$
P C I=C-\sum_{i=1}^{p} \sum_{j=1}^{m_{i}} a\left(T_{i}, S_{j}, D_{i j}\right) F(t, q)
$$

where:

C : maximum value of the condition index (perfect score).

a (T,S,D) : deduct value function that varies with the distress type (T), severity (S), and density (D).

$\mathrm{F}(\mathrm{t}, \mathrm{q}) \quad$ : an adjustment function that varies with the total deduct value ( $\mathrm{t}$ ) and number of deducts (q).

$\mathrm{i}, \mathrm{j} \quad$ : counters for the distress types and severity levels, respectively.

p : : total number of observed distress types.

m. : number of severity levels for the ith distress type. Typically, three levels of severity are used (low, medium, and high).

Pavement management systems involve collecting information on basic surface distresses and then using those distresses to calculate a pavement condition index (PCI). A pavement with no visual distresses rates 100. Points are deducted for each distress and adjusted for the both severity and extent of the distress to calculate the PCI for a sample of pavement.
Pavement Condition Report. This report provides the agency engineers with a pavement condition for the current status for each studied link. Also, it provides the condition of the individual pavement sections and the overall road pavement condition and repair needs. The pavement condition was calculated using the data from the inspections of the Aborshada road sections acquired by the author.

\subsubsection{Calculation of Pavement Condition Index for Aborshada Road}

The inputs to determine the required treatment for Aborshada Road, i.e., the condition survey data which includes distress quantity, severity, and condition index, was used. The optimal maintenance activities plan is arrived at using utilizing the pavement condition index. The pavement distress data was collected by the author during the month of March 2013. Random samples of the road were selected (22 samples), which represent about $10 \%$ of the road area. The road pavement was inspected to survey the different distresses in each sample unit. The pavement distresses were classified into 19 distresses according to the PCI standards as shown in Table 1. The surveyed data and PCI calculations for the samples and the road are shown in Tables 2 to 7 as an example of three samples. The results of the remaining samples are shown in Table 8.

\subsection{Pavement maintenance works for Aborshada Road}

The selection procedures of the maintenance works were based on the expected performance of the pavement and to eliminate some of the pavement distresses by suitable maintenance works. In general, many factors must be evaluated by a specifying agency when selecting a pavement maintenance treatment. These factors may includes : type and extent of the common distresses, cost of maintenance works, existing surface condition of the Aborshada Road pavement, and other project-specific conditions.

In this study, the Aborshada Road maintenance works were based on the type and extent of the most common distresses found on the pavement surface. The frequencies of the pavement distress numbers were $13,10,1,3,7,6,18$ and 9 in a descending percentage order as shown in Table 9. The major outcome of any pavement treatment program is to identify the best treatment for the sections in need of treatment. Also, pavement distresses govern the choice of the best treatment based on their types and severity.

Pavement performance is determined by both the degree and extent of any distress. So, types and degrees of distress should be considered in determining road maintenance activities and performing project level analysis. In this study case, the maintenance work alternatives were considered in Table 8, as follows:

Tab. 1 Distress classification and numbering according to ASTM (D6433-07).

\begin{tabular}{|l|c|c|c|c|c|}
\hline 1 & Alligator cracking & 8 & Jt, Reflection cracking & 15 & Rutting \\
\hline 2 & Bleeding & 9 & Lane/Shoulder Drop Off & 16 & Shoving \\
\hline 3 & Block cracking & 10 & Long \& Trans Cracking & 17 & Slippage Cracking \\
\hline 4 & Bumps and sags & 11 & Patching \& Util Cut Patching & 18 & Swell \\
\hline 5 & Corrugation & 12 & Polished Aggregate & 19 & Weathering/Raveling \\
\hline 6 & Depression & 13 & Potholes & & \\
\hline 7 & Edge cracking & 14 & Railroad Crossing & & \\
\hline
\end{tabular}


Tab. 2 Pavement Condition Data Sheet for Sample No.1, $M=5.59<9$.

\begin{tabular}{|c|c|c|c|c|c|c|c|c|c|c|c|c|c|c|c|c|c|c|}
\hline Distress & \multicolumn{15}{|c|}{ Quantity } & \multirow{2}{*}{$\begin{array}{c}\text { Total } \\
6\end{array}$} & \multirow{2}{*}{\begin{tabular}{|c|} 
Density \% \\
0.85 \\
\end{tabular}} & \multirow{2}{*}{$\begin{array}{c}\begin{array}{c}\text { Deduct } \\
\text { Value }\end{array} \\
\mathbf{5 0}\end{array}$} \\
\hline $13 H$ & 1 & 1 & 1 & 1 & 1 & 1 & & & & & & & & & & & & \\
\hline $1 \mathrm{M}$ & $3 * 6$ & $2 * 2$ & & & & & & & & & & & & & & 22 & 3.14 & 34 \\
\hline $13 M$ & 1 & 1 & 1 & 1 & 1 & 1 & 1 & 1 & & & & & & & & 8 & 1.14 & 31 \\
\hline $10 M$ & 7 & 11 & 6 & 4 & 7 & 6 & 7 & 13 & 7 & 3.5 & 4 & 6 & 10.5 & 13.5 & 7 & 112.5 & 16 & 24 \\
\hline $13 \mathrm{~L}$ & 1 & 1 & 1 & 1 & 1 & 1 & & & & & & & & & & 6 & 0.85 & 19 \\
\hline $3 \mathrm{M}$ & $4 * 17$ & $3 * 3$ & $4 * 5$ & & & & & & & & & & & & & 97 & 13.85 & 18 \\
\hline $7 M$ & 6 & 3 & 11 & & & & & & & & & & & & & 20 & 2.85 & 9 \\
\hline $6 \mathrm{~L}$ & $3 * 4$ & $2 * 4$ & & & & & & & & & & & & & & 20 & 2.85 & 8 \\
\hline 9L & 3 & 4.5 & 5.5 & & & & & & & & & & & & & 13 & 1.85 & 5 \\
\hline
\end{tabular}

Tab. 3 Calculation of Corrected PCI Value for Sample No. 1.

\begin{tabular}{|c|c|c|c|c|c|c|c|c|c|c|c|c|c|c|c|}
\hline & \multicolumn{9}{|c|}{ Deduct Value } & Total & Q & $\mathrm{CDV}$ & \multirow{10}{*}{ 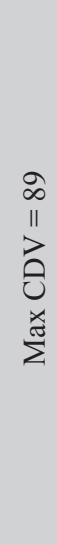 } & \multirow{10}{*}{ 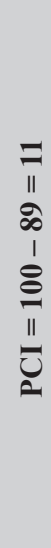 } & \multirow{10}{*}{ 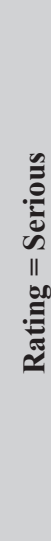 } \\
\hline 1 & 50 & 34 & 31 & 24 & 19 & 10.62 & 5.31 & 4.72 & 2.95 & 181.6 & 9 & 81 & & & \\
\hline 2 & 50 & 34 & 31 & 24 & 19 & 10.62 & 5.31 & 4.72 & 2 & 180.65 & 8 & 80 & & & \\
\hline 3 & 50 & 34 & 31 & 24 & 19 & 10.62 & 5.31 & 2 & 2 & 177.93 & 7 & 78 & & & \\
\hline 4 & 50 & 34 & 31 & 24 & 19 & 10.62 & 2 & 2 & 2 & 174.62 & 6 & 85 & & & \\
\hline 5 & 50 & 34 & 31 & 24 & 19 & 2 & 2 & 2 & 2 & 166 & 5 & 89 & & & \\
\hline 6 & 50 & 34 & 31 & 24 & 2 & 2 & 2 & 2 & 2 & 149 & 4 & 88 & & & \\
\hline 7 & 50 & 34 & 31 & 2 & 2 & 2 & 2 & 2 & 2 & 127 & 3 & 75 & & & \\
\hline 8 & 50 & 34 & 2 & 2 & 2 & 2 & 2 & 2 & 2 & 98 & 2 & 73 & & & \\
\hline 9 & 50 & 2 & 2 & 2 & 2 & 2 & 2 & 2 & 2 & 66 & 1 & 70 & & & \\
\hline
\end{tabular}

Tab. 4 Pavement Condition Data Sheet for Sample No.2, $M=5.96<7$.

\begin{tabular}{|c|c|c|c|c|c|c|c|c|c|c|c|c|c|c|c|c|c|c|c|c|}
\hline $\begin{array}{l}\text { Distress } \\
\text { Severity }\end{array}$ & \multicolumn{17}{|c|}{ Quantity } & \multirow{2}{*}{\begin{tabular}{|c|} 
Total \\
15 \\
\end{tabular}} & \multirow{2}{*}{\begin{tabular}{|c|}
$\begin{array}{c}\text { Density } \\
\%\end{array}$ \\
2.14 \\
\end{tabular}} & \multirow{2}{*}{$\begin{array}{c}\begin{array}{c}\text { Deduct } \\
\text { Value }\end{array} \\
46 \\
\end{array}$} \\
\hline $13 M$ & 1 & 1 & 1 & 1 & 1 & 1 & 1 & 1 & 1 & 1 & 1 & 1 & 1 & 1 & 1 & & & & & \\
\hline $13 H$ & 1 & 1 & 1 & 1 & & & & & & & & & & & & & & 4 & 0.571 & 40 \\
\hline $1 \mathrm{M}$ & $5 * 3$ & $3 * 2$ & $2 * 1.5$ & & & & & & & & & & & & & & & 24 & 3.428 & 35 \\
\hline $10 M$ & 3.5 & 6 & 2 & 3 & 2.5 & 3.5 & 7 & 9 & 7 & 6 & 11 & 3 & 3.5 & 7 & 9 & & 3.5 & 92.5 & 13.21 & 20 \\
\hline $13 \mathrm{~L}$ & 1 & 1 & 1 & 1 & 1 & 1 & & & & & & & & & & & & 6 & 0.857 & 19 \\
\hline $3 M$ & $2.5 * 3$ & $6 * 3$ & $4 * 3$ & & & & & & & & & & & & & & & \begin{tabular}{|l|}
37.5 \\
\end{tabular} & 5.357 & 12 \\
\hline $7 M$ & 4 & 5 & 3 & & & & & & & & & & & & & & & 12 & 1.71 & 4 \\
\hline $10 \mathrm{~L}$ & 2 & 4 & 2 & & & & & & & & & & & & & & & 8 & 1.14 & 2 \\
\hline
\end{tabular}

Tab. 5 Calculation of Corrected PCI Value for Sample No. 2.

\begin{tabular}{|c|c|c|c|c|c|c|c|c|c|c|c|c|c|}
\hline & \multicolumn{7}{|c|}{ Deduct Value } & Total & Q & $\mathrm{CDV}$ & \multirow{8}{*}{ 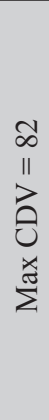 } & \multirow{8}{*}{ 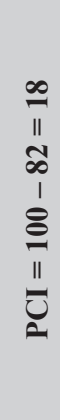 } & \multirow{8}{*}{ 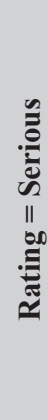 } \\
\hline 1 & 46 & 40 & 35 & 20 & 19 & 11.52 & 3.84 & 175.36 & 7 & 78 & & & \\
\hline 2 & 46 & 40 & 35 & 20 & 19 & 11.52 & 2 & 173.52 & 6 & 82 & & & \\
\hline 3 & 46 & 40 & 35 & & 20 & 19 & 2 & 164 & 5 & 75 & & & \\
\hline 4 & 46 & 40 & 35 & & 20 & 2 & 2 & 147 & 4 & 74 & & & \\
\hline 5 & 46 & 40 & 35 & 2 & 2 & 2 & 2 & 129 & 3 & 73 & & & \\
\hline 6 & 46 & 40 & 2 & 2 & 2 & 2 & 2 & 96 & 2 & 65 & & & \\
\hline 7 & 46 & 2 & 2 & 2 & 2 & 2 & 2 & 58 & 1 & 53 & & & \\
\hline
\end{tabular}


Tab 6. Pavement Condition Data Sheet for Sample No.3, $M=7.24>7$.

\begin{tabular}{|c|c|c|c|c|c|c|c|c|c|c|c|c|c|c|c|c|c|}
\hline $\begin{array}{l}\text { Distress } \\
\text { Severity }\end{array}$ & \multicolumn{14}{|c|}{ Quantity } & Total & Density & $\begin{array}{c}\text { Deduct } \\
\text { Value }\end{array}$ \\
\hline $13 M$ & 1 & 1 & 1 & 1 & 1 & 1 & 1 & 1 & & & & & & & 8 & 1.14 & 32 \\
\hline $13 H$ & 1 & 1 & & & & & & & & & & & & & 2 & 0.28 & 32 \\
\hline $1 M$ & $3 * 3$ & $4 * 2.5$ & & & & & & & & & & & & & 19 & 2.7 & 31 \\
\hline $13 \mathrm{~L}$ & 1 & 1 & 1 & 1 & 1 & 1 & 1 & & & & & & & & 7 & 1 & 20 \\
\hline $10 M$ & 7 & 3.5 & 3.5 & 4 & 7 & 7 & 8 & 7 & 4 & 7 & 5 & 4 & 7 & 3 & 77 & 11 & 19 \\
\hline $7 M$ & 22 & 17 & 6 & 3.5 & & & & & & & & & & & 48.5 & 6.92 & 13 \\
\hline $3 \mathbf{M}$ & $5 * 2.5$ & $3 * 4$ & & & & & & & & & & & & & 24.5 & 3.42 & 9 \\
\hline
\end{tabular}

Tab. 7 Calculation of Corrected PCI Value for Sample No. 3.

\begin{tabular}{|c|c|c|c|c|c|c|c|c|c|c|c|c|c|}
\hline & \multicolumn{7}{|c|}{ Deduct value } & Total & Q & $\mathrm{CDV}$ & \multirow{7}{*}{ 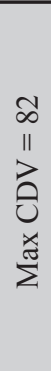 } & \multirow{7}{*}{ 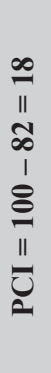 } & \multirow{7}{*}{ 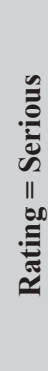 } \\
\hline 1 & 32 & 32 & 31 & 20 & 19 & 13 & 9 & 156 & 7 & 74 & & & \\
\hline 2 & 32 & 32 & 31 & 20 & 19 & 13 & 2 & 149 & 6 & 70 & & & \\
\hline 3 & 32 & 32 & 31 & 20 & 19 & 2 & 2 & 138 & 5 & 72 & & & \\
\hline 4 & 32 & 32 & 31 & 20 & 2 & 2 & 2 & 121 & 4 & 70 & & & \\
\hline 5 & 32 & 32 & 31 & 2 & 2 & 2 & 2 & 103 & 3 & 65 & & & \\
\hline 6 & 32 & 32 & 2 & 2 & 2 & 2 & 2 & 74 & 2 & 55 & & & \\
\hline
\end{tabular}

Tab. 8 PCI for Samples 1 to 22 for existing condition and distresses maintenance alternatives.

\begin{tabular}{|c|c|c|c|c|c|c|c|c|}
\hline \multirow{3}{*}{ Sample No. } & \multirow{2}{*}{\multicolumn{2}{|c|}{$\begin{array}{c}\text { Existing Condition } \\
\text { Case } 1\end{array}$}} & \multirow{2}{*}{\multicolumn{2}{|c|}{$\begin{array}{c}\text { Maintenance Alternative } 1 \\
\text { Case } 2\end{array}$}} & \multirow{2}{*}{\multicolumn{2}{|c|}{$\begin{array}{c}\text { Maintenance Alternative } 2 \\
\text { Case } 3\end{array}$}} & \multirow{2}{*}{\multicolumn{2}{|c|}{$\begin{array}{c}\text { Maintenance Alternative } 3 \\
\text { Case } 4 \\
\end{array}$}} \\
\hline & & & & & & & & \\
\hline & PCI & Rating & PCI & Rating & PCI & Rating & PCI & Rating \\
\hline 1 & 11 & Serious & 48 & Poor & 56 & Fair & 76 & Satisfactory \\
\hline 2 & 18 & Serious & 54 & Poor & 62 & Fair & 86 & Good \\
\hline 3 & 25 & Very Poor & 58 & Fair & 64 & Fair & 84 & Satisfactory \\
\hline 4 & 58 & Fair & 67 & Fair & 76 & Satisfactory & 76 & Satisfactory \\
\hline 5 & 60 & Fair & 76 & Satisfactory & 88 & Good & 90 & Good \\
\hline 6 & 8 & Failed & 62 & Fair & 68 & Fair & 68 & Fair \\
\hline 7 & 28 & Very Poor & 68 & Fair & 78 & Satisfactory & 78 & Satisfactory \\
\hline 8 & 58 & Fair & 66 & Fair & 71 & Satisfactory & 71 & Satisfactory \\
\hline 9 & 18 & Serious & 46 & Poor & 53 & Fair & 68 & Fair \\
\hline 10 & 20 & Serious & 52 & Poor & 58 & Fair & 84 & Satisfactory \\
\hline 11 & 44 & Poor & 44 & Poor & 48 & Poor & 82 & Satisfactory \\
\hline 12 & 50 & Poor & 56 & Fair & 66 & Fair & 75 & Satisfactory \\
\hline 13 & 43 & Poor & 54 & Poor & 56 & Fair & 84 & Satisfactory \\
\hline 14 & 57 & Fair & 66 & Fair & 82 & Satisfactory & 82 & Satisfactory \\
\hline 15 & 10 & Failed & 25 & Serious & 30 & Very Poor & 91 & Good \\
\hline 16 & 32 & Very Poor & 52 & Poor & 58 & Fair & 76 & Satisfactory \\
\hline 17 & 14 & Serious & 48 & Poor & 51 & Poor & 80 & Satisfactory \\
\hline 18 & 44 & Poor & 46 & Poor & 50 & Poor & 79 & Satisfactory \\
\hline 19 & 41 & Poor & 52 & Poor & 60 & Fair & 83 & Satisfactory \\
\hline 20 & 44 & Poor & 56 & Fair & 62 & Fair & 90 & Good \\
\hline 21 & 59 & Fair & 64 & Fair & 78 & Satisfactory & 82 & Satisfactory \\
\hline 22 & 48 & Poor & 68 & Fair & 86 & Good & 86 & Good \\
\hline $\begin{array}{c}\text { Road } \\
\text { Condition }\end{array}$ & 35.9 & Very Poor & 55.8 & Fair & 63.7 & Fair & 80.5 & Satisfactory \\
\hline
\end{tabular}


Tab. 9 Frequency of distress on the Aborshada Road pavement.

\begin{tabular}{|c|c|c|c|c|c|c|c|c|c|}
\hline No. of Pavement Distress & 13 & 10 & 1 & 3 & 7 & 6 & 18 & 9 & Other Distress \\
\hline Percent of samples & 95 & 90 & 81 & 81 & 68 & 18 & 9 & 5 & 0 \\
\hline
\end{tabular}

1 - Maintenance alternative No. 1, by eliminating pavement distress No. 13 "potholes", the road condition changed from very poor (35.9) to fair (55.8).

2 - Maintenance alternative No. 2, by eliminate pavement distresses Nos. 13 "potholes" and 10 "long. \& trans. cracking" , the road condition scale was raised from 55.8 to 63.7 but the rating did not change.

3 - Maintenance alternative No. 3, by eliminating pavement distresses Nos. 13, 10 and 1 "alligator cracking", the road condition changed from fair with a rating of 63.7 to a satisfactory condition with a rating of 80.5 .

\section{CONCLUSIONS AND RECOMMENDATIONS}

The major outcome of any pavement treatment program is to identify the best treatment for the sections in need of treatment. The outcome of this work is a practical output of the application of ASTM-D6433-07 for evaluating the Aborshada Road pavement condition in the Gharian area. Also, a determination of the optimum maintenance works was needed to improve the pavement condition. The existing road condition PCI was 35.9, and the rating was very poor. Also, specific conclusions can be drawn based on the observations. The most common pavement distresses were the following :
1. Potholes were observed throughout the length of the samples with high, medum and low severities.

2. Long. and transverse cracking was observed throughout the length of the samples with high, medum and low severities.

3. Alligator cracking was observed throughout the length of the samples with high, medum and low severities.

The best maintenance alternative for Aborshada Road was case No. 3 (Potholes, Long. \& Trans. Cracking and Alligator Crack Maintenance) by which the road condition became satisfactory (80.5). Based on the above findings, the following may be recommended to be considered by the highway agency :

1) Using automated survey techniques to reduce the labor needs and increase the safety of any personnel (in-house or contractor) that may conduct the surveys.

2) The Libyan Highway Agency must take maintenance by contracts into its consideration.

3) The evaluation of the pavement condition before and after maintenance by contract should be performed by a team of well-experienced engineers.

4) The time of maintenance is an important factor in the quality of the results obtained. Thus it is important that routine maintenance should always be performed before any pavement section reaches a poor condition. 


\section{REFERENCES}

American Society of Testing and Materials (ASTM) (1999) Standard Practice for Roads and Parking Lot Pavement Condition Index Surveys. ASTM D6433-99. American Society of Testing and Materials, West Conshocken, PA.

American Society of Testing and Materials (ASTM) (2007) Standard Practice for Roads and Parking Lot Pavement Condition Index Surveys. ASTM D6433-07. American Society of Testing and Materials, West Conshocken, PA.

Dessouky, S., Krugler, P. - Papagiannakis, A.T. - Freeman, T. (2011) Review of Best Practices for the Selection of Rehab And Preventive Maintenance Projects: Technical Report, Report No. FHWA/TX-11/0-6586-1. Report Date Published: April 2011.

Papagiannakis, A. - Gharaibeh, N. - Weissmann, J. - Wimsatt, A. (2009) Evaluation and Development of Pavement Scores, Performance Models and Needs Estimates. Report No. FHWA/TX-09/06386-1, Report Date January 2009. Published: February 2009.
Reza, F. - Boriboonsomsin, K. - Bazlamit, S. (2006) Development of a Pavement Quality Index for the State of Ohio. Paper for 85th Annual Meeting of The Transportation Research Board Washington, D.C. January 2006.

Shahin, M. Y. - Kohn, S.D. (1979) Development of a Pavement Condition Rating Procedure for Roads, Streets, and Parking Lots. Technical Report M-268, U.S. Army Construction Engineering Research Laboratory, Champaign, IL.

Wolters, A. - Grogg, M. - Zimmerman, K. - Cummingham, J. (2002) Distress Collection for the City of Philadelphia with an Emphasis on Assessing the Impact of Utility Patching on the Network. September 1, 2002. Available on <http://pms.nevadadot. com/2002.asp>.

Youssef, M.A. - Essam, A.S. (2001) A Two Fold Optimization System for Highway Maintenance Fund Allocation. $5^{\text {th }}$ International Conference on Managing Pavements, August, 2001, Seattle, Washington. ISBN 0971174016 